\title{
LIQUID-BASED CYTOLOGY AND ITS PRACTICABILITY IN BULGARIA
}

\author{
Atanas Tsonev, Stefan Ivanov, Emil Kovachev \\ Department of Obstetrics and Gynecology, Medical University of Varna
}

\begin{abstract}
PURPOSE: Our aim was to summarize the foreign and our own experience in screening the cervical cancer by using conventional Papanicolaou (PAP) smear and liquid-based cytology (LBC).

MATERIAL AND METHODS: In the Department of Obstetrics and Gynecology, Medical University of Varna, we examined 100 patients and compared the results from $\mathrm{LBC}$ with those from conventional PAP smear concerning different criteria as well as to test $\mathrm{LBC}$ practicability in Bulgaria.

RESULTS: There were significant advantages of LBC mainly due to the lower number of unsatisfactory results and higher specificity of low-grade squamous intraepithelial lesions (LSIL). The comparison with the results from foreign studies demonstrated the same tendencies and diagnostic values.

CONCLUSION: Our investigation proved the benefits of LBC in screening the cervical cancer. A much broader application of this method in Bulgaria was recommended taking into consideration that it was rarely used at presence.
\end{abstract}

Key words: cervical cancer, cervical precancer, liquid-based cytology, Papanicolaou smear, screening

\section{INTRODUCTION}

Since the advent of widespread Papanicolaou (PAP) smear screening in the United States during the 1950s, incidence and mortality rates of invasive cervical cancer dramatically decreased by more than $70 \%$. Worldwide, it is the second leading cause of cancer death in women. PAP test collects exfoliated cells from the surface of the cervix (10). Exfoliation occurs from most normal, precancerous, and cancerous cervical epithelium. It is the detection

\footnotetext{
Address for correspondence:

Atanas Tsonev, MD

Department of Obstetrics and Gynecology

Medical University of Varna

150 Tsar Osvoboditel Blvd.

9002 Varna, Bulgaria

e-mail:atanastsonev@yahoo.com
}

Received: August 30, 2012

Accepted: March 04, 2013 of precancerous cells that predates invasive disease by years and allows for cancer prevention. PAP test evolution is instructive in many aspects. First devised as a simple method to determine the reproductive cycle of laboratory animals by George Papanicolaou, it has evolved into a source of cellular material for sophisticated molecular and diagnostic techniques. Although apparently ever changing, the one consistent aspect of its past and future is the success that PAP screening has had in the prevention of invasive cervical cancer. Terminology was developed for squamous preinvasive disease and reflected its origin in the cervical epithelium. Cervical cancer is caused by a sexually transmitted disease, human papillomavirus (HPV) infection of the cervix. HPV infection is common among females, and some studies suggest that more than $70 \%$ of women will have had an infection by the end of their sexual experience. Infection with a highrisk type of HPV is a requisite for development 
of preinvasive and invasive squamous neoplasia of the cervix. Other risk factors include multiple sexual partners, intercourse at an early age, poor individual's hygiene, immunocompromises, other sexually transmitted diseases such as herpes simplex virus type and cigarette smoking $(1,11)$. Liquid-based PAP test is another method developed to improve the preservation and presentation of cells for cervical cytologic analysis. Basic technique of the method is shown on Fig. 1. standard procedures of fixation, we stained the slides after Romanovsky-Gimza method. The final slides were histologically evaluated. Bethesda System classification was applied for each histological result - Atypical squamous cells of undetermined significance (ASCUS), LSIL, high-grade squamous intraepithelial lesion (HSIL), and negative for intraepithelial lesion or malignancy (NILM) (13).

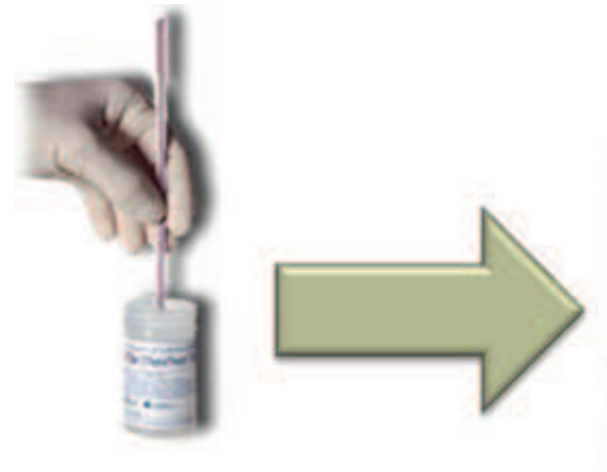

Specimen vial

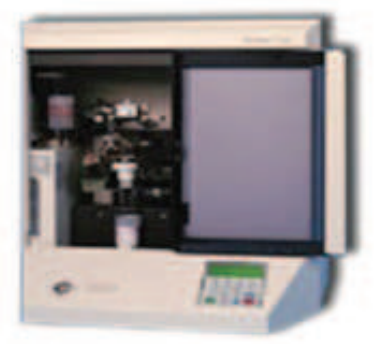

Thin Prep 2000

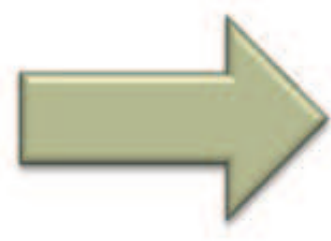

Final Slide

Fig. 1. Basic technique of liquid-based cytology

This method is more sensitive in detecting the cervical lesions than the conventional technique. It allows for the cellular material to be deposited in a liquid preservative that rinses the collection device, filters blood and mucus and fixes the cells.

\section{MATERIAL AND METHOD}

In the DepartmentofObstetricsandGynecology, Medical University of Varna, we examined 100 female patients by using LBC screening method for the purpose of detecting early cervical lesions. We compared the results from LBC with those from conventional PAP smear widely used in Bulgaria concerning different criteria. Besides we tested the practicability of this new method in Bulgaria $c$ and as well as to test LBC practicability. Our results were compared with those published by foreign authors, mainly from the USA, Australia and Scandinavian countries. The unit used for preparation of the samples was ThinPrep2000. After undergoing

\section{RESULTS}

Our results show a reduction by $67 \%$ of the unsatisfactory and by $15 \%$ of ASCUS rates compared to conventional PAP slides. LSIL detection is by three times higher than conventional PAP test, too. There is a higher detection rate of invasive cancer cases. However, taking into considerations the small number of invasive cancer patients, further tests need to be performed to evaluate the actual benefits of LBC over conventional PAP test.

There are significant advantages of LBC mainly due to the lower number of unsatisfactory results and higher specificity for LSIL. Liquid-based collection and processing provide more representative cervical sampling than conventional smearing of the specimen on a glass slide. When a conventional PAP smear test is collected, over $80 \%$ of the cells collected on the sampling device are not transferred to the slide. So, existing cervical cell abnormalities could be on the collection device after the sample is collected from 
the patient. However, they might never occur on the slide for diagnostic observation. The slide received will have missing cells and obscuring elements that limit diagnosis accuracy. This can cause a nonrepresentative sample that may not reflect patient's actual pathological condition. results our results demonstrate the same tendencies and values $(3,4,9)$. An Australian meta-analysis of LBC compared to conventional cytology is presented in Table 1.

\section{DISCUSSION}

The ThinPrep LBC test is the only PPAP test

Table 1. Comparative values of diagnostic categories by using conventional and liquid-based cytology

\begin{tabular}{lc|c|c|c|}
\hline & \multicolumn{2}{c|}{ Conventional cytology } & \multicolumn{2}{c|}{ Liquid-based cytology } \\
\cline { 2 - 5 } Diagnostic categories & \multicolumn{2}{c|}{$\mathrm{n}=688,035$} & $\mathrm{n}$ & $\mathrm{n}=562,662$ \\
\cline { 2 - 5 } & $\mathrm{n}$ & $\%$ & 518,878 & 92,22 \\
normal & 646,014 & 93,89 & 22,986 & 4,09 \\
ASCUS & 26,561 & 3,86 & 15,041 & 2,67 \\
LSIL & 10,236 & 1,49 & 5,348 & 0,95 \\
HSIL & 4,771 & 0,69 & 409 & 0,07 \\
cancer & 453 & 0,07 & & 0 \\
\hline
\end{tabular}

When using the ThinPrep LBC PAP test, virtually, $100 \%$ of cells collected in the sample device are transferred to the ThinPrep vial. The specimen is then sent to the laboratory, where an automated processor prepares the slide by dispersing and filtering the sample and then placing a representative sample on the slide. The process ensures that a representative portion of the patient's sample is placed on the microscope slide while reducing the obscuring blood, mucus, and non-diagnostic debris $(2,12)$. At the laboratory, the LBC System addresses screening errors, a main cause of false-negative results. Using the conventional method, a physician smears the sample collected from the patient onto a slide. This sample is commonly clouded with mucus and debris. When combined with a slide containing cells that are overlapping and clumped together, this results in a slide that is exceptionally difficult to read. With LBC, the physician needs only to send the vial containing the cell sample to the laboratory. There, a clear, easy-to-read slide sample that displays a thin layer of evenly distributed cells is produced (5-7).

Since FDA approval in 1996, more than 170 studies have been published in peer-reviewed medical journals, demonstrating the superiority of the LBC Pap Test in a clinical setting. Compared to foreign approved by the FDA as 'significantly more effective' than the conventional PAP smear for detection of cervical abnormalities. According to some studies, the ThinPrep LBC test improves the detection of precancerous cervical cells when compared with the conventional PAP smear. In the USA, more than $87 \%$ of the screening is performed by LBC. The ThinPrep LBC test possessees certificates of approval from the FDA and the European CE. It is the most widely used liquid-based PAP test as well in Ireland, Germany, and the UK. Nowadays it is applied in many other European countries as well as in Israel, Jordan and India. It allows for multiple observation of the vial and other testing procedures such as HPV and Chlamydia testing (8).

\section{CONCLUSION}

Taking into consideration the obvious benefits and 'easy-to-perform' technique of the LBC, the huge experience of foreign countries in using this revolutionary and proven method for screening for cervical lesions as well as our initial practical experience gained in the Department of Obstetrics and Gynecology, Medical University of Varna we could draw the following conclusions: 
1. LBC should be offered as a screening option to more patients in Bulgaria.

2. Bulgarian hospitals should routinely use LBC for cervical cancer screening.

3. Bulgarian pathologists should use Bethesda System classification as a main guideline during the histological evaluation of the cervical slides.

\section{REFERENCES}

1. American Cancer Society. Cancer facts and figures 1997-2005. Atlanta, GA, American Cancer Society, 1997-2005.

2. American Cancer Society. What are the key statistics about cervical cancer?- http://www.cancer. org/docroot/CRI/content/CRI_2_4_1X.

3. Ashfaq, R., D. Gibbons, C. Vela, M. H. Saboorian, F. Iliya. ThinPrep Pap Test. Accuracy for glandular disease.- Acta Cytol., 43, 1999, No 1, 81-5.

4. Bernstein, S. J., L. Sanchez-Ramos, B. Ndubisi. Liquid-based cervical cytologic smear study and conventional Papanicolaou smears: a metaanalysis of prospective studies comparing cytologic diagnosis and sample adequacy.- Am. J. Obstet. Gynecol., 185, 2001, No 2, 308-317.

5. Cytyc Corporation. The ThinPrep Pap Test package insert.

6. CDC Press Release. 13.XII.2007.

7. FUTURE II Study Group. Quadrivalent vaccine against human papillomavirus to prevent highgrade cervical lesions.- New Engl. J. Med., 356, 2007, No 19, 1915-1927.

8. Harper, D. M., E. L. Franco, C. M. Wheeler, A. B. Moscicki, B. Romanowski, C. M. Roteli-Martins, et al.; HPV Vaccine Study group. Sustained efficacy up to 4.5 years of a bivalent L1 virus-like particle vaccine against human papillomavirus types 16 and 18: follow-up from a randomised control trial.Lancet, 367, 2006, No 9518, 1247-1255.

9. Joura, E. A., S. Leodolter, M. Hernandez-Avila, C. M. Wheeler, G. Perez, L. A. Koutsky, et al.
Efficacy of a quadrivalent prophylactic human papillomavirus (types 6, 11, 16, and 18) L1 viruslike-particle vaccine against high-grade vulval and vaginal lesions: a combined analysis of three randomised clinical trials.- Lancet, 369, 2007, No 9574, 1693-702.

10. Koliopoulos, G., M. Arbyn, P. Martin-Hirsch, M. Kyrgiou, W. Prendiville, E. Paraskevaidis. Diagnostic accuracy of human papillomavirus testing in primary cervical screening: a systematic review and meta-analysis of non-randomized studies.- Gynecol. Oncol., 104, 2007, No 1, 232-246.

11. Koutsky, L. A., K. A. Ault, C. M. Wheeler, D. R. Brown, E. Barr, F. B. Alvarez, et al.; Proof of Principle Study Investigators. A controlled trial of a human papillomavirus type 16 vaccine.- New Engl. J. Med., 347, 2002, No 21, 1645-1651.

12. Solomon, D., D. Davey, R. Kurman, A. Moriarty, D. O'Connor, M. Prey, et al.; Forum Group Members; Bethesda 2001 Workshop. The 2001 Bethesda System: terminology for reporting results of cervical cytology.- JAMA, 287, 2002, No 16, 2114-2119.

13. Thrall, M. J., S. E. Pambuccian, E. B. Stelow, D. M. McKeon, L. Miller, K. Savik, et al. Impact of the more restrictive definition of atypical squamous cells introduced by the 2001 Bethesda System on the sensitivity and specificity of the Papanicolaou test: a 5-year follow-up study of Papanicolaou tests originally interpreted as ASCUS, reclassified according to Bethesda 2001 criteria.- Cancer, 114, 2008, No 3, 171-179. 